OPEN ACCESS

Edited by:

Ulrike Koehl,

Hannover Medical School, Germany

Reviewed by:

Ofer Mandelboim,

Hebrew University of

Jerusalem, Israe

Alexander Steinle,

Goethe University Frankfurt, Germany

*Correspondence:

Ralf Dressel

rdresse@gwdg.de

${ }^{+}$Antje Isernhagen and Dörthe Malzahn share first authorship.

Specialty section:

This article was submitted to Alloimmunity and Transplantation,

a section of the journal

Frontiers in Immunology

Received: 30 October 2016 Accepted: 28 November 2016 Published: 12 December 2016

Citation:

Isernhagen A, Malzahn D, Bickeböller $H$ and Dressel $R$ (2016) Impact of the MICA129Met/Val Dimorphism on NKG2D-Mediated Biological Functions and Disease Risks.

Front. Immunol. 7:588. doi: 10.3389/fimmu.2016.00588

\section{Impact of the MICA-129Met/Val Dimorphism on NKG2D-Mediated Biological Functions and Disease Risks}

\author{
Antje Isernhagen ${ }^{1 \dagger}$, Dörthe Malzahn ${ }^{2 \dagger}$, Heike Bickeböller ${ }^{2}$ and Ralf Dressel1,3* \\ 1 Institute of Cellular and Molecular Immunology, University Medical Center Göttingen, Göttingen, Germany, \\ ${ }^{2}$ Institute of Genetic Epidemiology, University Medical Center Göttingen, Göttingen, Germany, ${ }^{3}$ DZHK (German \\ Center for Cardiovascular Research), Partner Site Göttingen, Göttingen, Germany
}

The major histocompatibility complex (MHC) class I chain-related $\mathrm{A}(\mathrm{MICA})$ is the most polymorphic non-classical MHC class I gene in humans. It encodes a ligand for NKG2D (NK group 2, member D), an activating natural killer (NK) receptor that is expressed mainly on NK cells and $\mathrm{CD}^{+} \mathrm{T}$ cells. The single-nucleotide polymorphism (SNP) rs1051792 causing a valine (Val) to methionine (Met) exchange at position 129 of the MICA protein is of specific interest. It separates MICA into isoforms that bind NKG2D with high (Met) and low affinities (Val). Therefore, this SNP has been investigated for associations with infections, autoimmune diseases, and cancer. Here, we systematically review these studies and analyze them in view of new data on the functional consequences of this polymorphism. It has been shown recently that the MICA-129Met variant elicits a stronger NKG2D signaling, resulting in more degranulation and IFN- $\gamma$ production in NK cells and in a faster costimulation of $\mathrm{CD}^{+} \mathrm{T}$ cells than the MICA-129Val variant. However, the MICA-129Met isoform also downregulates NKG2D more efficiently than the MICA-129Val isoform. This downregulation impairs NKG2D-mediated functions at high expression intensities of the MICA-Met variant. These features of the MICA-129Met/ Val dimorphism need to be considered when interpreting disease association studies. Particularly, in the field of hematopoietic stem cell transplantation, they help to explain the associations of the SNP with outcome including graft-versus-host disease and relapse of malignancy. Implications for future disease association studies of the MICA-129Met/ Val dimorphism are discussed.

Keywords: NK cells, T cells, activating NK receptor, costimulation, single-nucleotide polymorphism, autoimmune diseases, cancer, hematopoietic stem cell transplantation

\section{INTRODUCTION}

The major histocompatibility complex (MHC) class I chain-related A (MICA) is the most polymorphic non-classical MHC class I gene in humans, and 105 alleles are known encoding for 82 protein variants (http://www.ebi.ac.uk/imgt/hla/, release 3.25.0). MICA is encoded within the human leukocyte antigen (HLA) complex close to HLA-B $(1,2)$. The protein structure is similar to classical class I molecules, but MICA is not associated with $\beta 2$-microglobulin and does not present peptides. MICA is constitutively expressed only on a few cell types, including gastrointestinal epithelium, but is induced due to cellular and genotoxic stress $(3,4)$, malignant transformation, or virus infection 
$(5,6)$. MICA is a ligand for NKG2D (NK group 2, member D), an activating natural killer (NK) receptor encoded by the KLRK1 gene (7). NKG2D is expressed on most human NK cells, CD ${ }^{+} \alpha \beta$ T cells, $\gamma \delta$ T cells, iNKT cells, and subsets of effector or memory $\mathrm{CD}^{+}{ }^{+} \mathrm{T}$ cells $(8,9)$. On NK cells, NKG2D signaling elicits killing of target cells (10) and secretion of IFN- $\gamma(11)$. On CD8 ${ }^{+}$ $\alpha \beta$ T cells, NKG2D provides a costimulatory signal to activate naïve cytotoxic T lymphocytes (12). NKG2D contributes to the elimination of tumor cells (13) and plays a role in the defense against pathogens $(14,15)$. In addition to MICA, MICB and the UL16-binding proteins (ULBP) encoded by the retinoic acid early transcript 1 (RAET1) family function as ligands for NKG2D. $M I C B$ is also very polymorphic with 42 alleles encoding 28 protein variants (http://www.ebi.ac.uk/imgt/hla/, release 3.25.0). The RAET1 gene family is localized on chromosome 6 outside the HLA complex and six loci encode functional proteins (16). RAET1 genes are less polymorphic than MICA and MICB.

Polymorphisms of MICA have been investigated for their role in infections, autoimmune diseases, and cancer (17-21). The single-nucleotide polymorphism (SNP) rs1051792 (G/A) causing a valine ( $\mathrm{Val}$ ) to methionine (Met) exchange at position 129 in the $\alpha 2$ domain of the MICA protein has gained specific interest. It separates MICA alleles into two groups (22). MICA isoforms containing a methionine at position 129 bind NKG2D with high affinity, whereas those with a valine bind NKG2D with low affinity. High-affinity alleles include $M I C A^{\star} 001,{ }^{\star} 002,{ }^{\star} 007$, and ${ }^{\star} 017$; among the low-affinity alleles are $M I C A^{\star} 004,{ }^{\star} 006,{ }^{\star} 008,{ }^{\star} 009$, and ${ }^{\star} 010$ (23). Due to its functional consequences, the MICA$129 \mathrm{Met} / \mathrm{Val}$ dimorphism has been investigated in several disease association studies. Here, we review these studies in view of new data on the functional consequences of this amino acid variation elicited after binding to NKG2D.

\section{MICA-129Met/Val DISEASE ASSOCIATION STUDIES}

In September 2016, we searched Pubmed for MICA-129Met/ Val disease association studies using the key words rs1051792, MICA-129, MICA AND polymorphism AND Met, and MICA AND polymorphism AND Val. Moreover, we exchanged polymorphism by SNP, Met by methionine, and Val by valine. We identified 17 publications, in which an association of the MICA-129Met/Val dimorphism with a disease or disease complication has been investigated. One study in Chinese language (24) appeared to be not independent of a larger study published in English (25). Thus, we analyzed 16 independent studies published between 2005 and 2015 (Table S1 in Supplementary Material). Three studies are small with less than 100 cases. All others are of a medium size with more than 100 but less than 1,000 patients included, and most studies used a case-control design.

Eight studies investigated associations with autoimmune diseases, i.e., ankylosing spondylitis (AS) (26), rheumatoid arthritis (RA) (27-29), inflammatory bowel disease (IBD) $(25,30)$ [including ulcerative colitis (UC) and Crohn's disease], systemic lupus erythematosus (SLE) (28), type I diabetes (31), latent autoimmune diabetes in adults (LADA) (31), and psoriasis (32). In one study, the MICA-129 SNP has not been determined directly. Instead, the
SNP rs 1051794 was typed and reported to be in complete linkage disequilibrium with the rs1051792 (27). Five studies reported on malignancies, i.e., nasopharyngeal cancer (33), hepatitis B virus (HBV)-induced hepatocellular carcinoma (HCC) (34), cutaneous malignant melanoma (35), and relapse of malignancy after hematopoietic stem cell transplantation (HSCT) $(36,37)$. Three studies investigated infections or their complications, i.e., HBV infection and HBV-induced HCC (34), left ventricular systolic dysfunction (LVSD) in chronic Chargas heart disease (38), and ocular toxoplasmosis (39). One study investigated an association of the MICA-129Met/Val dimorphism with recurrent miscarriage $(40)$. The two studies on HSCT $(36,37)$ investigated besides relapse also other outcomes including graft-versus-host disease (GVHD).

Three studies, on recurrent miscarriage (40), ocular toxoplasmosis (39), and malignant melanoma (35), failed to demonstrate an association with the SNP. Thus, $81 \%$ of the studies showed an association at least for a subgroup, e.g., juvenile AS, whereas in all patients with AS, the association was dependent on HLA-B27 (26), or a sub-phenotype, e.g., severe LVSD (38). However, we must assume that other negative association studies have not been published. In seven studies, a MICA-129 allele and the corresponding homozygous genotype were both associated with a disease risk $(25,28,29,31,32,34,38)$. The odds ratio (OR) was then always higher for the genotype than the allele. In six studies, the Met allele and/or the Met/Met genotype were found to be associated with a risk, including autoimmune diseases [juvenile AS (26), UC (30), SLE (28), and psoriasis (32)], a malignancy (HBV-induced HCC) (34), and a complication of an infection (severe LVSD in chronic Chargas disease) (38). In three studies, the $\mathrm{Val}$ allele and/or the $\mathrm{Val} / \mathrm{Val}$ genotype has been identified to confer a risk for autoimmune diseases [including RA (27), UC (25), and diabetes (31)] and for nasopharyngeal carcinoma (NPC) (33). Moreover, rheumatoid factor (RF) positivity in RA patients has been associated with the Val allele and the Val/ Val genotype (29). In the studies on HSCT, different outcomes showed different associations. In one study (36), the Met/Met genotype was associated with an increased risk of relapse and the $\mathrm{Val} / \mathrm{Val}$ genotype with an increased risk of chronic GVHD. In our recent study (37), the Met/Met genotype conferred a risk of acute GVHD, whereas having Met alleles reduced the risk to die from acute GVHD. Overall, the Val allele was associated with a higher mortality after HSCT (37).

The results of these disease association studies do not allow for a simple unifying interpretation, such as the high-affinity MICA-129Met variant being associated with an activation of the immune system resulting in a lower risk of infections and cancer but higher risk of autoimmunity (Figures 1A,B). Autoimmune diseases are associated with both variants even within the same disease entity. UC, e.g., has been associated with the Met/Met genotype in a small study from Spain (30) but with the $\mathrm{Val}$ allele and $\mathrm{Val} / \mathrm{Val}$ genotype in a larger study from China (25). RA has been associated with the Val allele in a study from France and Germany (27), but no association was found in cohorts from Japan (28) and Tunisia (29). Notably, a role of the NKG2D pathway has been reported for the pathogenesis of RA (41) and SLE (42), although this has not been linked to 


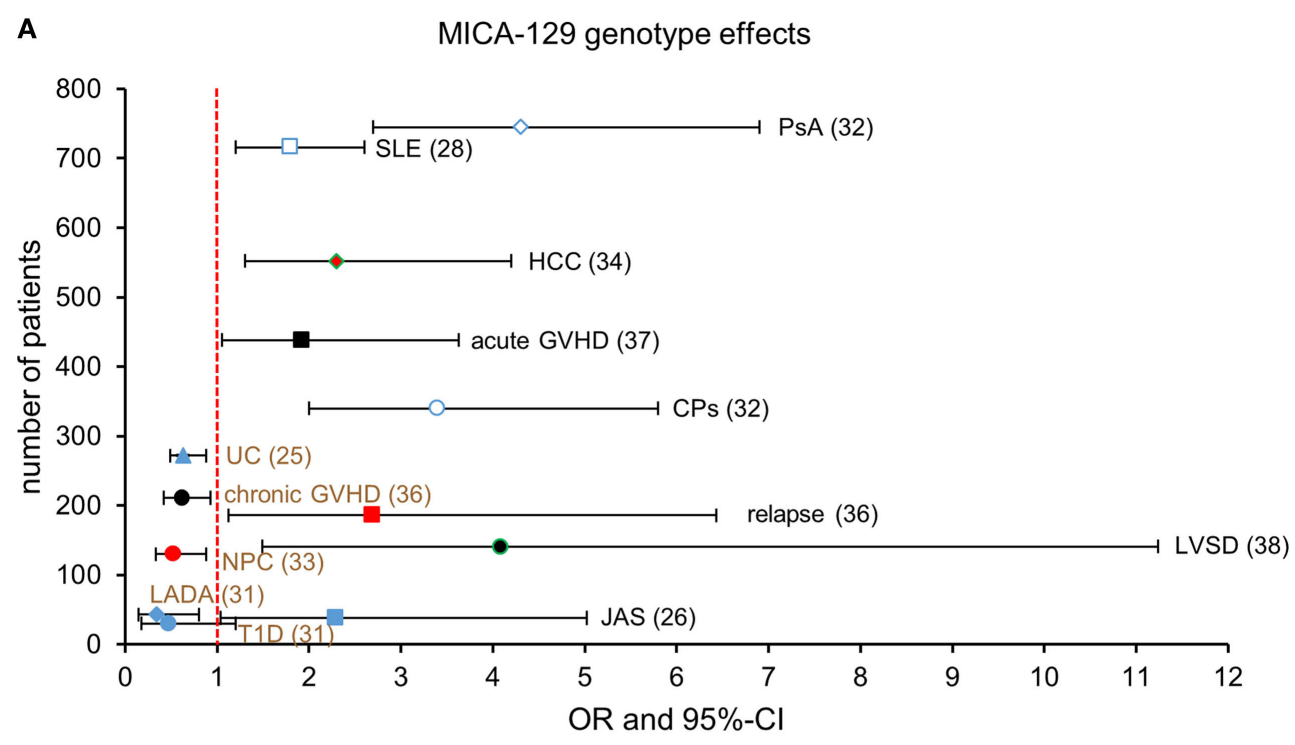

B

MICA-129 allele effects

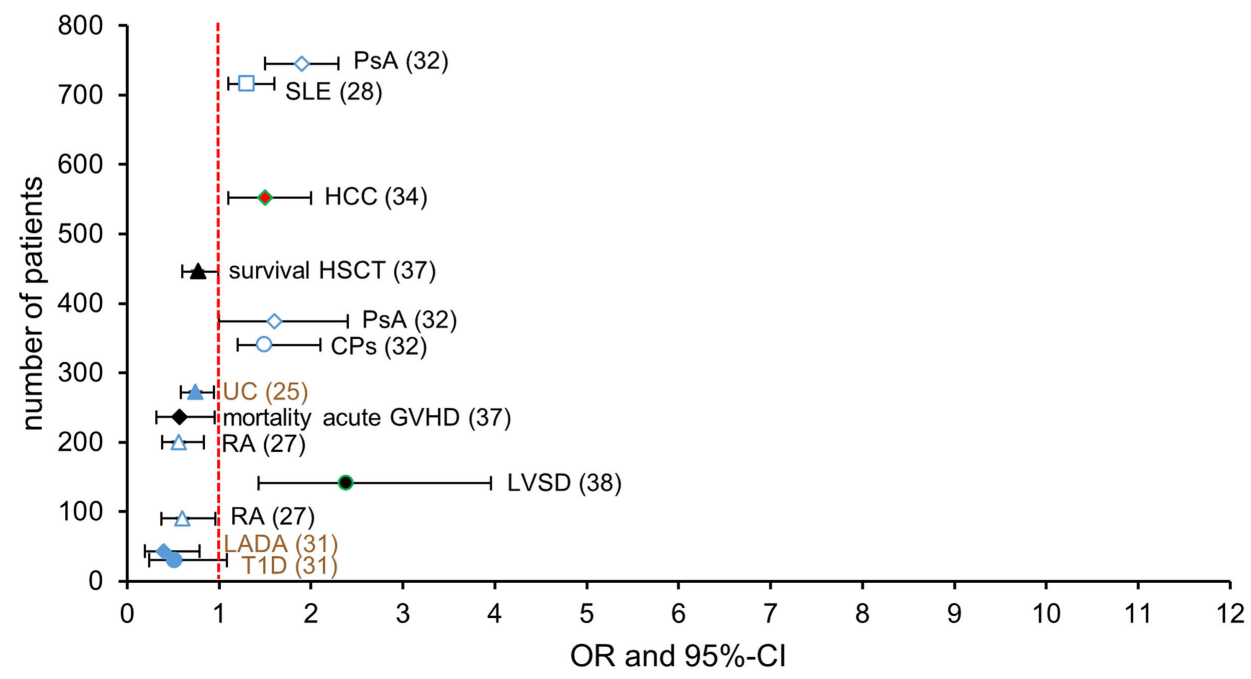

FIGURE 1 | Reported associations of the homozygous MICA-129 genotypes (A) and the MICA-129 alleles (B) with health risks [odds ratio (OR) > 1] or advantages (OR < 1). Shown are ORs with 95\% confidence intervals (CI) or hazard ratios reported by Boukouaci et al. (36) and Isernhagen et al. (37) (overall survival) in event-time data. The number of patients analyzed in the studies is indicated at the $y$-axis. Studies reporting on autoimmune diseases are shown by open and closed blue symbols and malignancies by red symbols; studies reporting complications of infections (LVSD, Chargas disease; HCC, hepatitis B virus infection) are shown by green frames, and others are displayed by black symbols. The investigated diseases or complications and the references for the studies are indicated. (A) MICA-129Met/Met genotype effects are directly displayed. For studies that reported MICA-129Val/Val genotype effects [chronic GVHD (36), NPC (33), UC (25), RA (27), T1D, and LADA (31), indicated by brown font], the graph displays the corresponding effect of the pooled MICA-129 Met/Met and MICA-129Met/Val genotypes to allow for a direct comparison. (B) MICA-129Met allele effects are directly displayed. For studies that reported MICA-129Val allele effects [UC (25), T1D, and LADA (31), indicated by brown font], the graph displays the corresponding effect of the MICA-129Met allele; ORMet = 1/ORVal and 95\%-CIMet = (1/CIVal, upper, 1/CIVal, lower). Abbreviations: CPs, cutaneous psoriasis; GVHD, graft-versus-host disease; HCC, hepatocellular carcinoma; JAS, juvenile ankylosing spondylitis; LADA, latent autoimmune diabetes in adults; LVSD, left ventricular systolic dysfunction; NPC, nasopharyngeal carcinoma; PsA, psoriatic arthritis; RA, rheumatoid arthritis; SLE, systemic lupus erythematosus; T1D, type 1 diabetes; UC, ulcerative colitis.

polymorphisms. Juvenile AS has been associated in a small study with the Met/Met genotype (26), and a larger sequencing study identified the $M I C A^{\star} 007: 01$ allele that encodes a methionine at position 129 as a risk allele for AS in both Caucasian and Han Chinese populations (43). However, $M I C A^{\star} 019$, encoding a valine-129, has been identified as the major risk allele in Han Chinese (43). Malignancies were found to be associated with $\mathrm{Val} / \mathrm{Val}$ genotype in the case of NPC (33) but with the Met/Met genotype in the case of relapse after HSCT (36). These different associations could suggest that the observed associations are 
random or dependent on the population studied. However, since the MICA-129Met/Val dimorphism is functional, it could also indicate that we need to better understand this function to predict its consequences in the pathophysiology of different diseases in various populations, which might be exposed to different interfering environmental factors. This assumption is supported by genome-wide association studies (GWAS), which have assigned disease risks for $\operatorname{NPC}(44), \operatorname{HCC}(45,46)$, cervical cancer $(47,48)$, and asthma (49) or advantages, such as HIV long-term non-progression (50) to the MICA gene region in an unbiased manner.

\section{FUNCTIONAL CONSEQUENCES OF THE MICA-129Met/Val DIMORPHISM}

It has been shown by Steinle and colleagues that MICA-129Met isoforms bind NKG2D with high affinity in contrast to MICA$129 \mathrm{Val}$ isoforms that bind with low affinity (22). Yoshida and colleagues combined the MICA-129Met variant with the A9 variant of a microsatellite polymorphism in the transmembrane (TM) region and the MICA-129Val variant with the A5-TM variant in GST-fusion proteins (28). NK92MI cells showed a reduced NKG2D expression and killed K562 cells less efficiently when exposed to the MICA-129Met-A9-TM variant, but IFN- $\gamma$ production was increased (28). We recently studied the consequences of binding of the two MICA-129 variants to NKG2D on primary $\mathrm{NK}$ cells and $\mathrm{CD}^{+} \mathrm{T}$ cells using cell lines transfected with expression constructs and recombinant Fc-fusion proteins differing only in amino acid 129 (37, 51). The recombinant MICA-129Met variant stimulated a stronger phosphorylation of SRC family kinases in NK cells than the MICA-129Val variant. Subsequently, the MICA-129Met ligand triggered more degranulation and IFN- $\gamma$ production than the MICA-129Val ligand (Figure 2A). We then exposed NK cells to target cells expressing different amounts of the MICA-129 variants. The extent of degranulation and IFN- $\gamma$ secretion correlated positively with the MICA expression intensity on the target cells but only for the MICA-129Val isoform. The expression intensity of the MICA-129Met isoform, in contrast, had either none or even a negative effect on the extent of degranulation, target cell killing, and IFN- $\gamma$ release (37). On $\mathrm{CD}^{+} \mathrm{T}$ cells, the MICA$129 \mathrm{Met}$ isoform induced an earlier costimulatory activation than the MICA-129Val isoform (Figure 2B). Importantly, the MICA-129Met ligand induced also a stronger downregulation of NKG2D on both NK and CD8 ${ }^{+}$T cells than the MICA-129Val ligand. This downregulation of NKG2D impaired the capability of $\mathrm{NK}$ and $\mathrm{CD}^{+} \mathrm{T}$ cells to receive signals via NKG2D (37). Thus, MICA-129Met ligands, which elicit strong NKG2D responses, stimulate in parallel a robust negative feedback signal by downregulation of NKG2D that limits the initially stronger effects of MICA-129Met ligands. These data show that the biological effect of the MICA-129Met/Val dimorphism changes with the MICA expression intensity. Variant MICA-129Met triggers more NKG2D signals at low expression intensities, whereas variant MICA-129Val elicits more NKG2D effects at high expression, at which the MICA-129Met variant already downregulates NKG2D leading to impaired function. Thus, the biological effect of the SNP can hardly be predicted without information on the expression intensity of MICA.

It is known that expression intensities vary for certain $M I C A$ alleles $(52,53)$. The $G$ allele of the SNP at -1878 (rs2596542) in the promoter region of the MICA gene region, e.g., was found to have a higher transcriptional activity (54). Biological effects of the MICA-129Met/Val dimorphism can be expected to be modified by polymorphisms affecting MICA gene expression. We have investigated whether the Met/Val dimorphism itself affects MICA expression. In transfected cells, more of the MICA129Met variant was retained in intracellular compartments (51). A similar alteration of the intracellular transport has been described for MICA-A5.1 variants (55). Thus, the combination of polymorphisms affecting transcription and intracellular transport of MICA could modify the effect of the Met/Val dimorphism.

Another important aspect of MICA is the generation of soluble MICA (sMICA) by proteolytic shedding. sMICA can induce NKG2D downregulation $(56,57)$ resulting in tumor immune escape (58). Some MICA polymorphisms have been reported to affect the amounts of sMICA in sera of patients including the SNP at -1878 (rs2596542) in the promoter region $(34,45$, 59) that affects transcription (54), a microsatellite in exon 5 encoding the TM region $(60,61)$, and the MICA-129Met/Val dimorphism. In patients with UC, the MICA-129Val/Val genotype was associated with higher sMICA serum levels (25), and the MICA-129Val allele was also associated with higher sMICA serum levels in HBV patients and controls (34). In transfected cells, we found that the MICA-129Met isoform was more susceptible to shedding than the MICA-129Val isoform (51). However, due to the intracellular retention of the MICA-129Met variant (51), less sMICA might appear in sera $(25,34)$. Notably, intracellular retention and preferred shedding both appear to limit the expression of the high-affinity MICA-129Met isoform at the plasma membrane.

\section{MICA-129Met/Val DISEASE ASSOCIATIONS IN VIEW OF BIOLOGICAL FUNCTIONS}

Recent data on the MICA-129Met/Val variation demonstrate the complexity of the functional consequences of this exchange of a single amino acid $(37,51)$. There are several layers of this complexity, which are as follows: (1) the function of the variant is not constant but dynamic (37); it depends on the MICA expression intensity, and the direction of the biological effect can invert for the MICA-129Met variant at higher expression. (2) Epistatic effects must be expected for this SNP as polymorphisms affecting the expression of MICA will modify the functional effects of the MICA-129Met/Val isoforms. Moreover, the expression intensity of NKG2D can be modified by SNPs in the KLRK1 gene (62) and those might interact with the MICA-129 variants. Other genes within the NKG2D pathway including other ligands might also show epistatic effects (63). (3) MICA can target NKG2D on several cell types, and biological effects on different cell types might be synergistic or antagonistic. An activation of NK cells and a costimulation of $\mathrm{CD} 8^{+} \mathrm{T}$ cells both can promote antitumor 
A

MICA-129Val

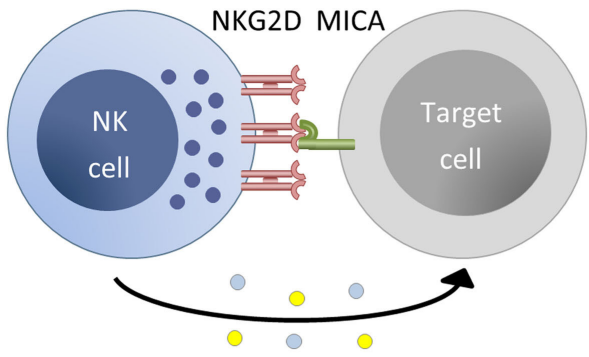

IFN $y$ and cytotoxic mediators

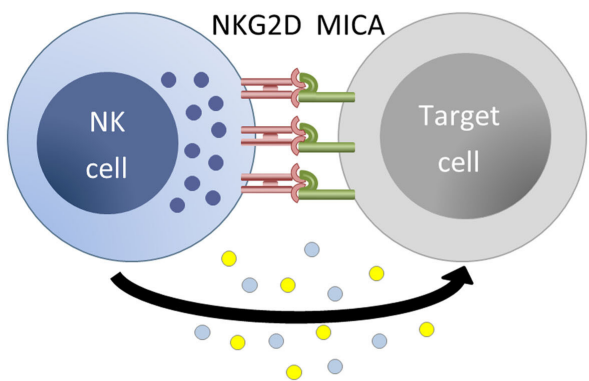

B

MICA-129Val

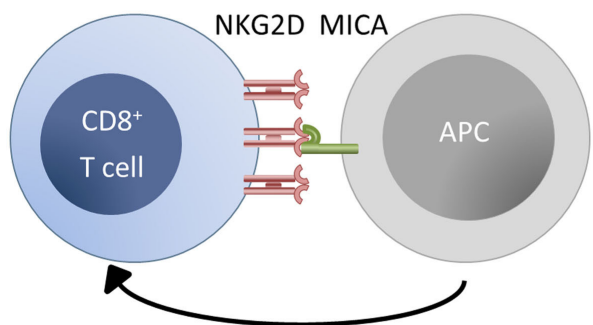

antigen-dependent co-stimulation

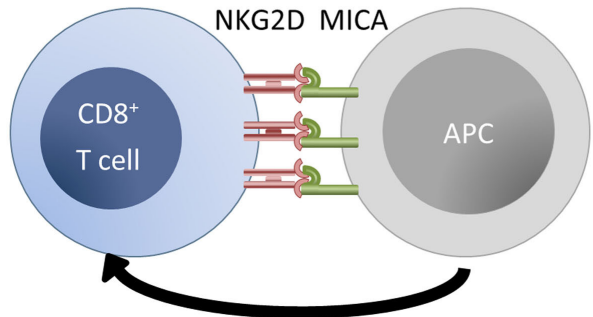

MICA-129Met

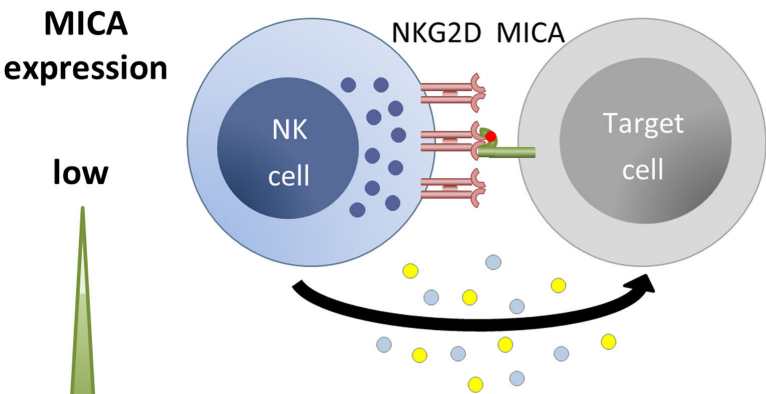

IFN $\gamma$ and cytotoxic mediators

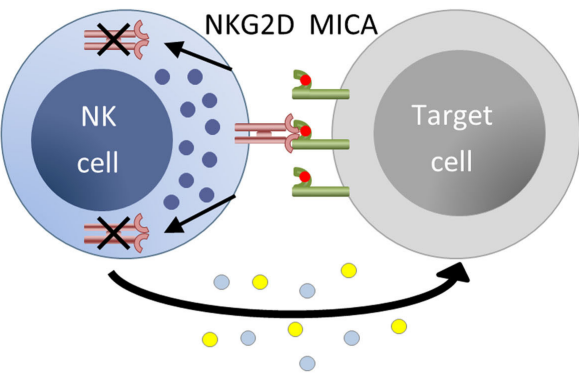

MICA-129Met
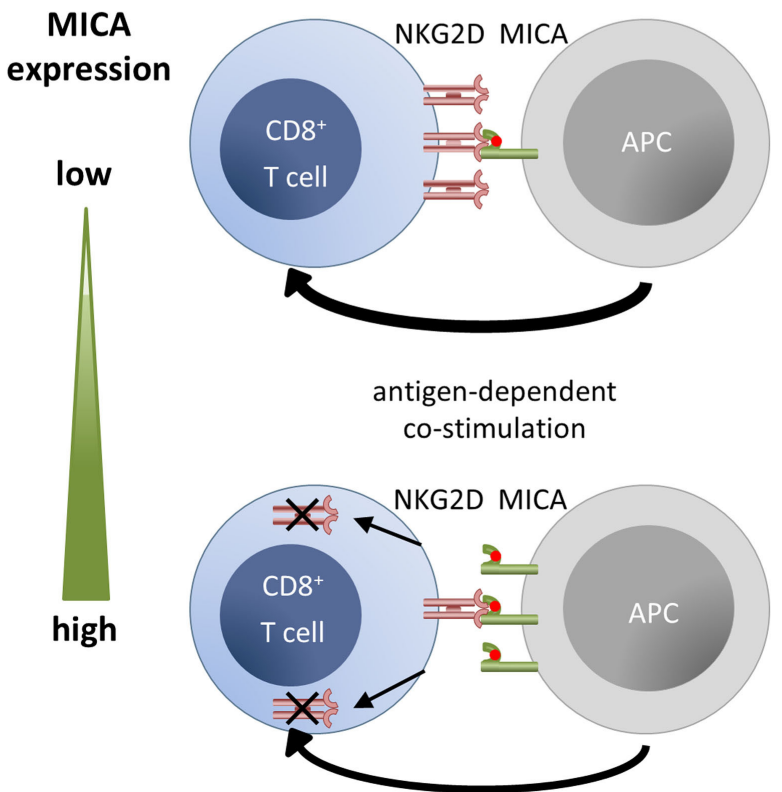

FIGURE 2 | Summary of functional effects of MICA-129 variants depending on expression intensity. (A) For target cells expressing the MICA-129Val variant, the degree of natural killer (NK) cell cytotoxicity and IFN- $\gamma$ production increases steadily with the MICA expression intensity. Augmented expression of the high-affinity MICA-129Met isoform, in contrast, has none or even a negative effect on these NK cell functions due to a rapid downregulation of NKG2D on NK cells. (B) Antigen-dependent costimulation of $C D 8^{+} T$ cells with the MICA-129Met variant allows for an earlier antigen-dependent activation than costimulation with the MICA-129Val variant. However, the downregulation of NKG2D in response to MICA-129Met ligands impairs any subsequent NKG2D-dependent costimulation and T cell activation. The downregulation of NKG2D on CD8 ${ }^{+}$T cells is augmented with MICA-129Met expression intensity. The figure is reproduced from Isernhagen et al. (37). 
immunity. By contrast, a strong activation of NK cells might polarize an immune response to $\mathrm{Th}_{1}$ reaction and reduce the risk to develop a $\mathrm{Th}_{2}$-mediated autoimmune disease. (4) Additional factors, such as sMICA or anti-MICA antibodies (36) that might neutralize sMICA, have been shown to be functionally important and have been determined in some of the disease association studies $(25,34,36)$.

Currently, we mostly have not sufficient clinical and biological information to interpret the MICA-129Met/Val disease association studies in view of the complex function of this polymorphism. However, the two HSCT studies do provide more information and illustrate the clinical effects of the MICA-129Met/Val dimorphism as explained previously in detail (37). In our study (37), the homozygous carriers of Met alleles had an increased risk to experience acute GVHD, possibly due to immediate strong effects of MICA-129Met variants on NKG2D signaling. Having at least one Met allele reduced the risk to die from acute GVHD likely due to a rapid downregulation of NKG2D on alloreactive $\mathrm{CD}^{+} \mathrm{T}$ cells mediated by engagement of a high-affinity MICA-129Met variant. Carrying a MICA-129Met allele increased in consequence the chance of survival in all patients and in patients receiving a MICA129-matched graft (37). Boukouaci and colleagues reported an increased risk of chronic GVHD for recipients with the $\mathrm{Val} / \mathrm{Val}$ genotype, whereas the Met/Met genotype was associated with the risk of relapse (36). Sustained NKG2D-mediated activation of alloreactive $\mathrm{CD} 8^{+} \mathrm{T}$ cells would be expected if only MICA-129Val variants are present that fail to efficiently downregulate NKG2D, and this could increase the risk of chronic GVHD but reduce the risk of relapse. Thus, the different risk associations reported in the two studies are not arguing against the relevance of the MICA-129 dimorphism for the outcome of HSCT. The principal relevance of the NKG2D pathway for HSCT is further emphasized by studies showing an effect of the genotype of the NKG2D ligand RAET1L (64) and NKG2D itself (65) on the survival of patients. Moreover, matching for MICA alleles (66-69) and specifically for the MICA-129 polymorphism (70) is beneficial in HSCT. The huge effect of MICA-129 matching appears hardly explainable solely by the avoidance of a potential minor histocompatibility antigen. A "tuning" of the threshold of NKG2D signaling toward the affinity of NKG2D ligands present in an individual (52) and disturbance of this balance by mismatching could be considered as an alternative explanation.

Despite the functional relevance of the MICA-129 SNP, it cannot be excluded that some of the associations reported are random or caused by linkage disequilibrium with classical HLA genes. The association of MICA-129 with psoriasis (32) has been disproven in large GWAS cohorts (71). However, associations with NPC (33) and HCC (34) are supported by GWAS data pointing to the MICA gene region (44-46).

\section{CONCLUSION}

Information on functional consequences of a polymorphism is indispensable for understanding disease associations. The variation in the disease associated allele or genotype of MICA-129 in the published studies must not indicate random associations. For $M I C A-129$, the biological function can change with expression intensity, epistatic interactions can be expected, the effect on different lymphocytes can vary, and modifying factors, such as sMICA, have to be considered. Notably, as expected for a functional SNP with a minor allele (MICA-129Met) frequency ranging from $48 \%$ in Africans to $30 \%$ in Asians (72), and being even the major allele reported in one of the analyzed studies (26), both alleles appear to confer advantages and disadvantages in specific situations suggesting balancing evolution of the MICA alleles. Since the MICA-129 dimorphism is considered as decisive for distinguishing low- and high-affinity variants (22), the frequency of alleles encoding high-affinity MICA variants is expected to match the frequency of the MICA-129Met variant. However, other MICA polymorphisms and their interaction need to be studied further (73).

In future studies, the MICA-129Met/Val dimorphism should be analyzed in larger cohorts. Detailed clinical information would help to understand why associations might differ in cohorts. Additional biological information should be obtained in parallel to genetic data. Most important would be data on MICA expression intensities in relevant tissues at relevant time points. Due to the complexity of MICA-129Met/Val effects, this polymorphism is unlikely to become a simple genetic biomarker for prediction of disease risks. However, it still may provide highly important information. We found that $\mathrm{Val} / \mathrm{Val}$ genotype carriers undergoing HSCT specifically profited from a treatment with antithymocyte globulin to deplete T cells (37). This might be explained by a lack of a high-affinity MICA variant that efficiently downregulates NKG2D on alloreactive donor $\mathrm{CD}^{+}{ }^{+} \mathrm{T}$ cells. Moreover, the MICA129 dimorphism might be relevant when considering therapies aiming at upregulation of MICA on tumor cells to sensitize them for NK cells $(74,75)$. Increasing the expression of MICA-129Met variants could result in opposite effects than intended.

\section{AUTHOR CONTRIBUTIONS}

RD searched the literature; RD and $\mathrm{AI}$ interpreted the functional data; $\mathrm{RD}$ and $\mathrm{DM}$ interpreted the genetic association data; $\mathrm{RD}$ drafted the manuscript; AI, DM, and HB commented the draft; and all the authors approved the final version.

\section{ACKNOWLEDGMENTS}

The authors thank all the colleagues who contributed to their studies on the MICA-129Met/Val dimorphism.

\section{FUNDING}

The authors' work was supported by the Deutsche Forschungsgemeinschaft (GRK 1034 and SFB 1002, TP C05) and the European Union Grant FP7-PEOPLE-2012-ITN-315963 (CELLEUROPE). They acknowledge support by the Open Access Publication Funds of the Göttingen University.

\section{SUPPLEMENTARY MATERIAL}

The Supplementary Material for this article can be found online at http://journal.frontiersin.org/article/10.3389/fimmu.2016.00588/ full\#supplementary-material. 


\section{REFERENCES}

1. Bahram S, Bresnahan M, Geraghty DE, Spies T. A second lineage of mammalian major histocompatibility complex class I genes. Proc Natl Acad Sci US A (1994) 91:6259-63. doi:10.1073/pnas.91.14.6259

2. Leelayuwat C, Townend DC, Degli-Esposti MA, Abraham LJ, Dawkins RL. A new polymorphic and multicopy MHC gene family related to nonmammalian class I. Immunogenetics (1994) 40:339-51. doi:10.1007/BF01246675

3. Groh V, Bahram S, Bauer S, Herman A, Beauchamp M, Spies T. Cell stressregulated human major histocompatibility complex class I gene expressed in gastrointestinal epithelium. Proc Natl Acad Sci U S A (1996) 93:12445-50. doi:10.1073/pnas.93.22.12445

4. Gasser S, Orsulic S, Brown EJ, Raulet DH. The DNA damage pathway regulates innate immune system ligands of the NKG2D receptor. Nature (2005) 436:1186-90. doi:10.1038/nature03884

5. Champsaur M, Lanier LL. Effect of NKG2D ligand expression on host immune responses. Immunol Rev (2010) 235:267-85. doi:10.1111/j.01052896.2010.00893.x

6. Raulet DH, Gasser S, Gowen BG, Deng W, Jung H. Regulation of ligands for the NKG2D activating receptor. Annu Rev Immunol (2013) 31:413-41. doi:10.1146/annurev-immunol-032712-095951

7. Glienke J, Sobanov Y, Brostjan C, Steffens C, Nguyen C, Lehrach H, et al. The genomic organization of NKG2C, E, F, and D receptor genes in the human natural killer gene complex. Immunogenetics (1998) 48:163-73. doi:10.1007/ s002510050420

8. Zafirova B, Wensveen FM, Gulin M, Polic B. Regulation of immune cell function and differentiation by the NKG2D receptor. Cell Mol Life Sci (2011) 68:3519-29. doi:10.1007/s00018-011-0797-0

9. Lanier LL. NKG2D receptor and its ligands in host defense. Cancer Immunol Res (2015) 3:575-82. doi:10.1158/2326-6066.CIR-15-0098

10. Billadeau DD, Upshaw JL, Schoon RA, Dick CJ, Leibson PJ. NKG2D-DAP10 triggers human NK cell-mediated killing via a Syk-independent regulatory pathway. Nat Immunol (2003) 4:557-64. doi:10.1038/ni929

11. Andre P, Castriconi R, Espeli M, Anfossi N, Juarez T, Hue S, et al. Comparative analysis of human NK cell activation induced by NKG2D and natural cytotoxicity receptors. Eur J Immunol (2004) 34:961-71. doi:10.1002/eji. 200324705

12. Groh V, Rhinehart R, Randolph-Habecker J, Topp MS, Riddell SR, Spies T. Costimulation of CD8alphabeta $\mathrm{T}$ cells by NKG2D via engagement by MIC induced on virus-infected cells. Nat Immunol (2001) 2:255-60. doi:10.1038/85321

13. Guerra N, Tan YX, Joncker NT, Choy A, Gallardo F, Xiong N, et al. NKG2Ddeficient mice are defective in tumor surveillance in models of spontaneous malignancy. Immunity (2008) 28:571-80. doi:10.1016/j.immuni.2008. 02.016

14. Fang M, Lanier LL, Sigal LJ. A role for NKG2D in NK cell-mediated resistance to poxvirus disease. PLoS Pathog (2008) 4:e30. doi:10.1371/journal. ppat.0040030

15. Wesselkamper SC, Eppert BL, Motz GT, Lau GW, Hassett DJ, Borchers MT. NKG2D is critical for NK cell activation in host defense against Pseudomonas aeruginosa respiratory infection. J Immunol (2008) 181:5481-9. doi:10.4049/ jimmunol.181.8.5481

16. Radosavljevic M, Cuillerier B, Wilson MJ, Clement O, Wicker S, Gilfillan S, et al. A cluster of ten novel MHC class I related genes on human chromosome 6q24.2-q25.3. Genomics (2002) 79:114-23. doi:10.1006/geno.2001.6673

17. Choy MK, Phipps ME. MICA polymorphism: biology and importance in immunity and disease. Trends Mol Med (2010) 16:97-106. doi:10.1016/ j.molmed.2010.01.002

18. Chen D, Gyllensten U. MICA polymorphism: biology and importance in cancer. Carcinogenesis (2014) 35:2633-42. doi:10.1093/carcin/bgu215

19. Goto K, Kato N. MICA SNPs and the NKG2D system in virus-induced HCC. J Gastroenterol (2015) 50:261-72. doi:10.1007/s00535-014-1000-9

20. Ji M, Wang J, Yuan L, Zhang Y, Zhang J, Dong W, et al. MICA polymorphisms and cancer risk: a meta-analysis. Int J Clin Exp Med (2015) 8:818-26.

21. Wang Q, Zhou X. Associations of MICA polymorphisms with inflammatory rheumatic diseases. Open Rheumatol J (2015) 9:94-100. doi:10.2174/187431 2901409010094

22. Steinle A, Li P, Morris DL, Groh V, Lanier LL, Strong RK, et al. Interactions of human NKG2D with its ligands MICA, MICB, and homologs of the mouse
RAE-1 protein family. Immunogenetics (2001) 53:279-87. doi:10.1007/ s002510100325

23. Stastny P. Introduction: MICA/MICB in innate immunity, adaptive immunity, autoimmunity, cancer, and in the immune response to transplants. Hum Immunol (2006) 67:141-4. doi:10.1016/j.humimm.2006.02.019

24. Zhao J, Jiang Y, Lei Y, Chen LP, Yi FM, Wang CG, et al. [The relationship between major histocompatibility complex class I chain-related antigens A (MICA)-129 gene polymorphism, soluble MICA level and ulcerative colitis]. Zhonghua Nei Ke Za Zhi (2011) 50:311-5.

25. Zhao J, Jiang Y, Lei Y, Zou K, Wang C, Huang S, et al. Functional MICA129 polymorphism and serum levels of soluble MICA are correlated with ulcerative colitis in Chinese patients. J Gastroenterol Hepatol (2011) 26:593-8. doi:10.1111/j.1440-1746.2010.06524.x

26. Amroun H, Djoudi H, Busson M, Allat R, El Sherbini SM, Sloma I, et al. Early-onset ankylosing spondylitis is associated with a functional MICA polymorphism. Hum Immunol (2005) 66:1057-61. doi:10.1016/j.humimm. 2005.09.004

27. Kirsten H, Petit-Teixeira E, Scholz M, Hasenclever D, Hantmann H, Heider D, et al. Association of MICA with rheumatoid arthritis independent of known HLA-DRB1 risk alleles in a family-based and a case control study. Arthritis Res Ther (2009) 11:R60. doi:10.1186/ar2683

28. Yoshida K, Komai K, Shiozawa K, Mashida A, Horiuchi T, Tanaka Y, et al. Role of the MICA polymorphism in systemic lupus erythematosus. Arthritis Rheum (2011) 63:3058-66. doi:10.1002/art.30501

29. Achour Y, Kammoun A, Ben Hamad M, Mahfoudh N, Chaabane S, Marzouk S, et al. Association study of MICA gene polymorphisms with rheumatoid arthritis susceptibility in south Tunisian population. Int J Immunogenet (2014) 41:486-92. doi:10.1111/iji.12146

30. Lopez-Hernandez R, Valdes M, Lucas D, Campillo JA, Martinez-Garcia $\mathrm{P}$, Salama H, et al. Association analysis of MICA gene polymorphism and MICA-129 dimorphism with inflammatory bowel disease susceptibility in a Spanish population. Hum Immunol (2010) 71:512-4. doi:10.1016/j. humimm.2010.02.003

31. Raache R, Belanteur K, Amroun H, Benyahia A, Heniche A, Azzouz M, et al. Association of major histocompatibility complex class 1 chain-related gene a dimorphism with type 1 diabetes and latent autoimmune diabetes in adults in the Algerian population. Clin Vaccine Immunol (2012) 19:557-61. doi:10.1128/CVI.05473-11

32. Pollock RA, Chandran V, Pellett FJ, Thavaneswaran A, Eder L, Barrett J, et al. The functional MICA-129 polymorphism is associated with skin but not joint manifestations of psoriatic disease independently of HLA-B and HLA-C. Tissue Antigens (2013) 82:43-7. doi:10.1111/tan.12126

33. Douik H, Ben Chaaben A, Attia Romdhane N, Romdhane HB, Mamoghli T, Fortier C, et al. Association of MICA-129 polymorphism with nasopharyngeal cancer risk in a Tunisian population. Hum Immunol (2009) 70:45-8. doi:10.1016/j.humimm.2008.10.008

34. Tong HV, Toan NL, Song LH, Bock CT, Kremsner PG, Velavan TP. Hepatitis $B$ virus-induced hepatocellular carcinoma: functional roles of MICA variants. J Viral Hepat (2013) 20:687-98. doi:10.1111/jvh.12089

35. Campillo JA, Lopez-Hernandez R, Martinez-Banaclocha H, Bolarin JM, Gimeno L, Mrowiec A, et al. MHC class I chain-related gene a diversity in patients with cutaneous malignant melanoma from southeastern Spain. Dis Markers (2015) 2015:831864. doi:10.1155/2015/831864

36. Boukouaci W, Busson M, Peffault De Latour R, Rocha V, Suberbielle C, Bengoufa D, et al. MICA-129 genotype, soluble MICA, and anti-MICA antibodies as biomarkers of chronic graft-versus-host disease. Blood (2009) 114:5216-24. doi:10.1182/blood-2009-04-217430

37. Isernhagen A, Malzahn D, Viktorova E, Elsner L, Monecke S, von Bonin F, et al. The MICA-129 dimorphism affects NKG2D signaling and outcome of hematopoietic stem cell transplantation. EMBO Mol Med (2015) 7:1480-502. doi:10.15252/emmm.201505246

38. Ayo CM, Oliveira AP, Camargo AV, Mattos CC, Bestetti RB, Mattos LC. Association of the functional MICA-129 polymorphism with the severity of chronic Chagas heart disease. Clin Infect Dis (2015) 61:1310-3. doi:10.1093/ cid/civ540

39. Ayo CM, Camargo AV, Frederico FB, Siqueira RC, Previato M, Murata FH, et al. MHC class I chain-related gene a polymorphisms and linkage disequilibrium with HLA-B and HLA-C alleles in ocular toxoplasmosis. PLoS One (2015) 10:e0144534. doi:10.1371/journal.pone.0144534 
40. Hizem S, Mtiraoui N, Massaoudi S, Fortier C, Boukouaci W, Kahina A, et al. Polymorphisms in genes coding for the NK-cell receptor NKG2D and its ligand MICA in recurrent miscarriage. Am J Reprod Immunol (2014) 72:577-85. doi:10.1111/aji.12314

41. Groh V, Bruhl A, El-Gabalawy H, Nelson JL, Spies T. Stimulation of T cell autoreactivity by anomalous expression of NKG2D and its MIC ligands in rheumatoid arthritis. Proc Natl Acad Sci U S A (2003) 100:9452-7. doi:10.1073/ pnas. 1632807100

42. Dai Z, Turtle CJ, Booth GC, Riddell SR, Gooley TA, Stevens AM, et al. Normally occurring NKG2D+CD4+ T cells are immunosuppressive and inversely correlated with disease activity in juvenile-onset lupus. J Exp Med (2009) 206:793-805. doi:10.1084/jem.20081648

43. Zhou X, Wang J, Zou H, Ward MM, Weisman MH, Espitia MG, et al. MICA, a gene contributing strong susceptibility to ankylosing spondylitis. Ann Rheum Dis (2014) 73:1552-7. doi:10.1136/annrheumdis-2013-203352

44. Low JS, Chin YM, Mushiroda T, Kubo M, Govindasamy GK, Pua KC, et al. A genome wide study of copy number variation associated with nasopharyngeal carcinoma in Malaysian Chinese identifies CNVs at $11 \mathrm{q} 14.3$ and 6p21.3 as candidate loci. PLoS One (2016) 11:e0145774. doi:10.1371/journal. pone. 0145774

45. Kumar V, Kato N, Urabe Y, Takahashi A, Muroyama R, Hosono N, et al. Genome-wide association study identifies a susceptibility locus for HCVinduced hepatocellular carcinoma. Nat Genet (2011) 43:455-8. doi:10.1038/ ng. 809

46. Chen K, Shi W, Xin Z, Wang H, Zhu X, Wu X, et al. Replication of genome wide association studies on hepatocellular carcinoma susceptibility loci in a Chinese population. PLoS One (2013) 8:e77315. doi:10.1371/journal.pone. 0077315

47. Chen D, Juko-Pecirep I, Hammer J, Ivansson E, Enroth S, Gustavsson I, et al. Genome-wide association study of susceptibility loci for cervical cancer. J Natl Cancer Inst (2013) 105:624-33. doi:10.1093/jnci/djt051

48. Chen D, Cui T, Ek WE, Liu H, Wang H, Gyllensten U. Analysis of the genetic architecture of susceptibility to cervical cancer indicates that common SNPs explain a large proportion of the heritability. Carcinogenesis (2015) 36:992-8. doi:10.1093/carcin/bgv083

49. Nieuwenhuis MA, Siedlinski M, Van Den Berge M, Granell R, Li X, Niens $\mathrm{M}$, et al. Combining genomewide association study and lung eQTL analysis provides evidence for novel genes associated with asthma. Allergy (2016) 71(12):1712-20. doi:10.1111/all.12990

50. Le Clerc S, Delaneau O, Coulonges C, Spadoni JL, Labib T, Laville V, et al. Evidence after imputation for a role of MICA variants in nonprogression and elite control of HIV type 1 infection. J Infect Dis (2014) 210:1946-50. doi:10.1093/infdis/jiu342

51. Isernhagen A, Schilling D, Monecke S, Shah P, Elsner L, Walter L, et al. The MICA-129Met/Val dimorphism affects plasma membrane expression and shedding of the NKG2D ligand MICA. Immunogenetics (2016) 68:109-23. doi:10.1007/s00251-015-0884-8

52. Shafi S, Vantourout P, Wallace G, Antoun A, Vaughan R, Stanford M, et al. An NKG2D-mediated human lymphoid stress surveillance response with high interindividual variation. Sci Transl Med (2011) 3:113ra124. doi:10.1126/ scitranslmed.3002922

53. Shi C, Li H, Couturier JP, Yang K, Guo X, He D, et al. Allele specific expression of MICA variants in human fibroblasts suggests a pathogenic mechanism. Open Rheumatol J (2015) 9:60-4. doi:10.2174/187431290 1409010060

54. Lo PH, Urabe Y, Kumar V, Tanikawa C, Koike K, Kato N, et al. Identification of a functional variant in the MICA promoter which regulates MICA expression and increases HCV-related hepatocellular carcinoma risk. PLoS One (2013) 8:e61279. doi:10.1371/journal.pone.0061279

55. Ashiru O, Lopez-Cobo S, Fernandez-Messina L, Pontes-Quero S, Pandolfi R, Reyburn HT, et al. A GPI anchor explains the unique biological features of the common NKG2D-ligand allele MICA*008. Biochem J (2013) 454:295-302. doi:10.1042/BJ20130194

56. Groh V, Wu J, Yee C, Spies T. Tumour-derived soluble MIC ligands impair expression of NKG2D and T-cell activation. Nature (2002) 419:734-8. doi:10.1038/nature01112

57. Salih HR, Rammensee HG, Steinle A. Cutting edge: down-regulation of MICA on human tumors by proteolytic shedding. J Immunol (2002) 169:4098-102. doi:10.4049/jimmunol.169.8.4098
58. El-Gazzar A, Groh V, Spies T. Immunobiology and conflicting roles of the human NKG2D lymphocyte receptor and its ligands in cancer. JImmunol (2013) 191:1509-15. doi:10.4049/jimmunol.1301071

59. Kumar V, Yi Lo PH, Sawai H, Kato N, Takahashi A, Deng Z, et al. Soluble MICA and a MICA variation as possible prognostic biomarkers for HBVinduced hepatocellular carcinoma. PLoS One (2012) 7:e44743. doi:10.1371/ journal.pone.0044743

60. Tamaki S, Kawakami M, Yamanaka Y, Shimomura H, Imai Y, Ishida J, et al. Relationship between soluble MICA and the MICA A5.1 homozygous genotype in patients with oral squamous cell carcinoma. Clin Immunol (2009) 130:331-7. doi:10.1016/j.clim.2008.09.004

61. Jiang X, Zou Y, Huo Z, Yu P. Association of major histocompatibility complex class I chain-related gene A microsatellite polymorphism and hepatocellular carcinoma in South China Han population. Tissue Antigens (2011) 78:143-7. doi:10.1111/j.1399-0039.2011.01693.x

62. Hayashi T, Imai K, Morishita Y, Hayashi I, Kusunoki Y, Nakachi K. Identification of the NKG2D haplotypes associated with natural cytotoxic activity of peripheral blood lymphocytes and cancer immunosurveillance. Cancer Res (2006) 66:563-70. doi:10.1158/0008-5472.CAN-05-2776

63. Isernhagen A, Malzahn D, Monecke S, Schilling D, Shah P, Multhoff G, et al. Functional consequences of genetic polymorphisms in the NKG2D receptor signaling pathway and putative gene interactions. Receptors Clin Investig (2016) 3:e1269. doi:10.14800/rci.1269

64. Antoun A, Vekaria D, Salama RA, Pratt G, Jobson S, Cook M, et al. The genotype of RAET1L (ULBP6), a ligand for human NKG2D (KLRK1), markedly influences the clinical outcome of allogeneic stem cell transplantation. Br J Haematol (2012) 159:589-98. doi:10.1111/bjh.12072

65. Espinoza JL, Takami A, Onizuka M, Sao H, Akiyama H, Miyamura K, et al. NKG2D gene polymorphism has a significant impact on transplant outcomes after HLA-fully-matched unrelated bone marrow transplantation for standard risk hematologic malignancies. Haematologica (2009) 94:1427-34. doi:10.3324/haematol.2009.008318

66. Kitcharoen K, Witt CS, Romphruk AV, Christiansen FT, Leelayuwat C. MICA, MICB, and MHC beta block matching in bone marrow transplantation relevance to transplantation outcome. Hum Immunol (2006) 67:238-46. doi:10.1016/j.humimm.2006.02.012

67. Parmar S, Del Lima M, Zou Y, Patah PA, Liu P, Cano P, et al. Donor-recipient mismatches in MHC class I chain-related gene A in unrelated donor transplantation lead to increased incidence of acute graft-versus-host disease. Blood (2009) 114:2884-7. doi:10.1182/blood-2009-05-223172

68. Askar M, Sun Y, Rybicki L, Zhang A, Thomas D, Kalaycio M, et al. Synergistic effect of major histocompatibility complex class I-related chain a and human leukocyte antigen-DPB1 mismatches in association with acute graft-versushost disease after unrelated donor hematopoietic stem cell transplantation. Biol Blood Marrow Transplant (2014) 20:1835-40. doi:10.1016/j.bbmt. 2014.07.019

69. Carapito R, Jung N, Kwemou M, Untrau M, Michel S, Pichot A, et al. Matching for the nonconventional MHC-I MICA gene significantly reduces the incidence of acute and chronic GVHD. Blood (2016) 128:1979-86. doi:10.1182/ blood-2016-05-719070

70. Fuerst D, Neuchel C, Niederwieser D, Bunjes D, Gramatzki M, Wagner E, et al. Matching for the MICA-129 polymorphism is beneficial in unrelated hematopoietic stem cell transplantation. Blood (2016). doi:10.1182/blood2016-05-716357

71. Okada Y, Han B, Tsoi LC, Stuart PE, Ellinghaus E, Tejasvi T, et al. Fine mapping major histocompatibility complex associations in psoriasis and its clinical subtypes. Am J Hum Genet (2014) 95:162-72. doi:10.1016/j.ajhg.2014. 07.002

72. Cunningham F, Amode MR, Barrell D, Beal K, Billis K, Brent S, et al. Ensembl 2015. Nucleic Acids Res (2015) 43:D662-9. doi:10.1093/nar/gku1010

73. Carapito R, Bahram S. Genetics, genomics, and evolutionary biology of NKG2D ligands. Immunol Rev (2015) 267:88-116. doi:10.1111/imr.12328

74. Kato N, Tanaka J, Sugita J, Toubai T, Miura Y, Ibata M, et al. Regulation of the expression of MHC class I-related chain A, B (MICA, MICB) via chromatin remodeling and its impact on the susceptibility of leukemic cells to the cytotoxicity of NKG2D-expressing cells. Leukemia (2007) 21:2103-8. doi:10.1038/ sj.leu. 2404862

75. Diermayr S, Himmelreich H, Durovic B, Mathys-Schneeberger A, Siegler U, Langenkamp $\mathrm{U}$, et al. NKG2D ligand expression in AML increases in response 
to HDAC inhibitor valproic acid and contributes to allorecognition by NK-cell lines with single KIR-HLA class I specificities. Blood (2008) 111:1428-36. doi:10.1182/blood-2007-07-101311

Conflict of Interest Statement: The authors declare that the research was conducted in the absence of any commercial or financial relationships that could be construed as a potential conflict of interest.
Copyright (c) 2016 Isernhagen, Malzahn, Bickeböller and Dressel. This is an open-access article distributed under the terms of the Creative Commons Attribution License (CC BY). The use, distribution or reproduction in other forums is permitted, provided the original author(s) or licensor are credited and that the original publication in this journal is cited, in accordance with accepted academic practice. No use, distribution or reproduction is permitted which does not comply with these terms. 